

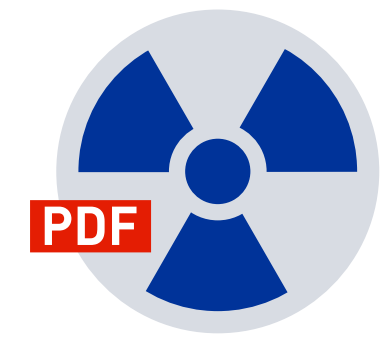

\section{REALOBJECTS PDFreactor $^{\oplus}$}

\section{Evaluation Version}

This PDF document was created by an evaluation version of RealObjects PDFreactor 10.2.10722. The evaluation version is fully functional, but includes this information page. It must not be used for production purposes. The information page and all other evaluation notices must not be removed from the PDF file.

NOTE: Conversions in evaluation mode might be slower and the results might have a larger file size than in production mode.

\section{Buy PDFreactor}

PDFreactor has detected 4 CPU cores, which means you need 1 license pack to use PDFreactor.

To buy a PDFreactor license follow this link:

\section{Buy PDFreactor online}

\section{About PDFreactor}

RealObjects PDFreactor is a powerful formatting processor for converting HTML and XML documents into PDF. It uses Cascading Style Sheets (CSS) to define page layout and styles. The server-side tool enables a great variety of applications in the fields of ERP, eCommerce and Electronic Publishing.

PDFreactor supports HTML5, CSS3 and JavaScript.

It allows you to dynamically generate PDF documents such as invoices, delivery notes and shipping documents on-the-fly. PDFreactor allows you to easily add server-based PDF generation functionality to your application or service. Since PDFreactor runs on a server, the end-user in general does not need any software other than a PDF viewer.

For more information visit www.pdfreactor.com 

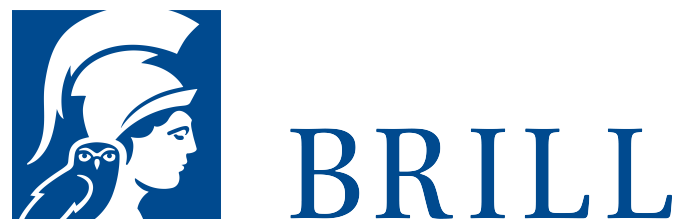

\section{Unresolved Border, Land and Maritime Disputes in Southeast Asia}

Bi- and Multilateral Conflict Resolution Approaches and ASEAN's Centrality

Editors: Alfred Gerstl and Mária Strašáková

Unresolved Border, Land and Maritime Disputes in Southeast Asia, edited by Alfred Gerstl and Mária Strašáková, sheds light on various unresolved and lingering territorial disputes in Southeast Asia and their reflection in current inter-state relations in the region. The authors, academics from Europe and East Asia, particularly address the territorial disputes in the South China Sea and those between Vietnam and Cambodia and Thailand and Cambodia. They apply International Relations theories in a wider regional and comparative perspective. The empirical analyses are embedded in a concise theoretical discussion of the principles of sovereignty, territorial integrity and borders. Furthermore, the book discusses the role of the Association of Southeast Asian Nations (ASEAN) and other multitrack mechanisms in border conflict mediation.

Contributors are: Petra Andělová, Alica Kizeková, Filip Kraus, Josef Falko Loher, Padraig Lysaght, Jörg Thiele, Richard Turcsányi, Truong-Minh Vu and Zdeněk Kř́žz.

\section{Readership}

Academics (and their students), diplomats and governmental officials, think tank analysts, NGOs, journalists focusing on Southeast Asia, and anyone concerned with current events in international relations and security; as well as specialists on the Southeast Asian region and International Relations scholars interested in border conflicts in general. 


\title{
Biographical Note
}

Alfred Gerstl, Dr. (1998), University of Vienna, and Master of International Relations (2004), Macquarie University Sydney, is lecturer and researcher at the Department of East Asia Studies at the University of Vienna. His research focuses on regional cooperation, conflicts and the notion of security in Southeast Asia.

Mária Strašáková, Ph.D. (2011), Charles University, works at the Department of Asian Studies at Metropolitan University Prague. She has published monographs and articles on security issues in Asia, including The South China Sea Dispute in International Relations (MUP Press, 2011).

For more information see brill.com

\author{
Order information: Order online at brill.com \\ +44330 333 oo49 | customerservices@brill.com \\ Submission information: brill.com/authors
}

Titles published by Brill | Fink, Brill | mentis or Brill | Schöningh: +49(o)715413279216| brill@brocom.de 